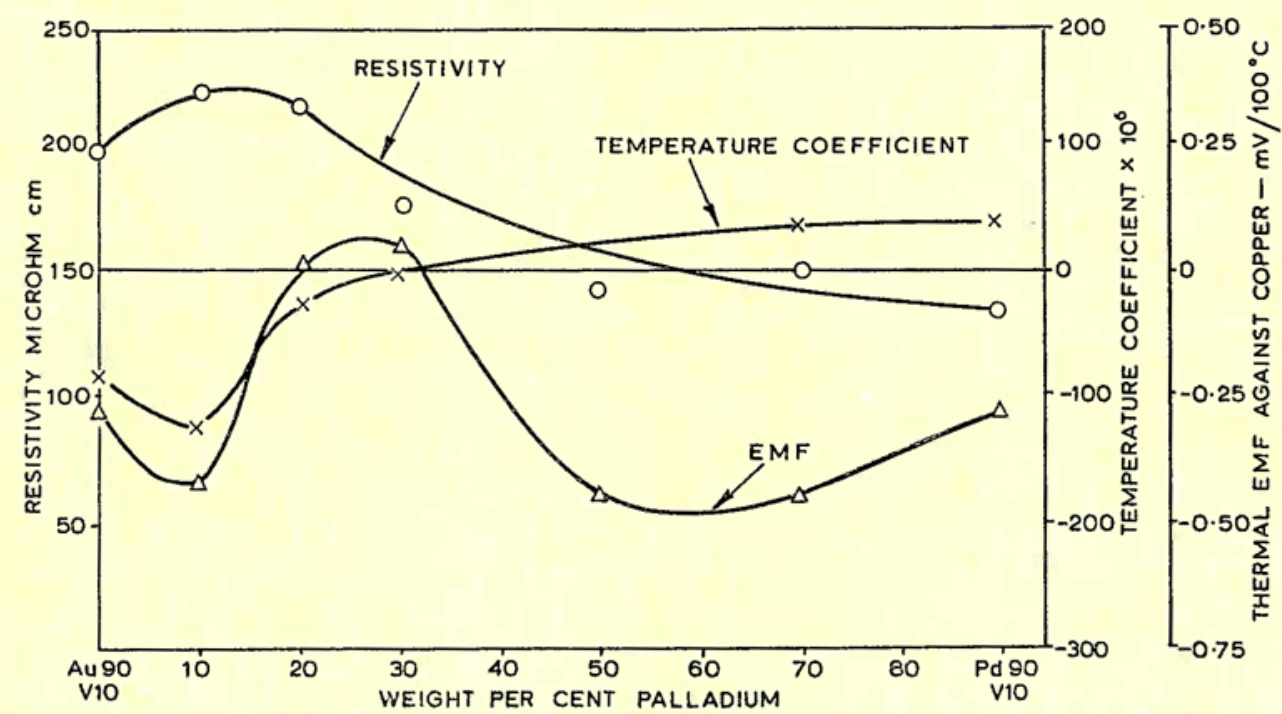

Fig. 7 The resistivity, temperature coefficient and thermal e.m.f.s of alloys in the ternary system with 10 per cent vanadium. At 20 per cent palladium it will be seen that an alloy is obtained having an excellent combination of properties

The alloy chosen for commercial development is that containing 10 per cent vanadium, 20 per cent palladium, balance gold. From the results in Figure 7 it will be readily seen that this material gives the optimum combination of properties, and it is at present undergoing development trials in a number of instrumental applications.

\section{References}

1 A. S. Darling, Gold Bulletin, 1972, 5, (4) 2

2 W. Köster and H. Nordskog, Z. Metallk., 1960, 51, 501

3 W. Köster and W. D. Haeh1, Z. Metallk., 1958, 49, 647

4 W. Köster, H. Kehrer and W. Rothenbacher, Z. Metallk., 1961, 52, 672

5 W. Köster, H. P. Rave and Y. Takeuchi, Z. Metallk., $1962, \mathbf{5 3}, 749$

\title{
The Catalytic Properties of Palladium-Gold Alloys
}

The view has previously been expressed in this journal that the very properties which make gold both so useful and so attractive in appearance militate against its having widespread and useful catalytic properties. It has, however, a useful role to play in moderating the properties of the much more vigorously active metals, such as platinum and especially palladium, with which it forms a continuous range of solid solutions. A lengthy review on "The Structure and Catalytic Properties of Palladium-Silver and Palladium-Gold Alloys", published recently by Dr E. G Allison and Professor G. C. Bond of Brunel University (1), provides a very full survey of the literature concerning the part which the Group IB metals exercise in altering the characteristics of the more active partner.

The over-riding impression gained from this review is that most of the catalytic work has been performed with forms of alloys which could not possibly be used in industrial processes - foils, wires and evaporated alloy films are frequently mentioned. Only very little seems to have been done using supported palladiumgold alloys, and much of this work stems from the patent literature and is therefore incompletely validated. There is clearly scope for much more research using carefully characterised supported alloys.

There are two theoretical approaches to describing how gold alters the catalytic properties of palladium.
The older idea, first propounded by Sir Neville Mott in the 1930s, states that gold's s-electrons enter the unfilled $d$-band of palladium, with consequent and proven effects on the latter's magnetic susceptibility and possibly on its catalytic capabilities. The newer idea, due to Wolfgang Sachtler of the Shell Laboratories in Amsterdam, suggests that the behaviour of an alloy surface is described by the arithmetic sum of the properties of the separate palladium and gold atoms. Thus for example one palladium atom surrounded by gold atoms will not behave in the same way as when surrounded by its own kind. This has been advanced as an explanation of the truly remarkable increase in selectivity for the oxidation of ethylene to acetaldehyde over alloy powders containing 60 to 85 per cent gold.

A further intriguing notion is that the surface composition of an alloy can change under the influence of adsorption, becoming enriched in whichever component interacts more strongly with the adsorbed species.

The review serves to indicate the wealth of unexplored possibilities which exist for gold to be beneficially employed in tempering the catalytic activity of other metals, notably by improving the selectivity with which intermediate oxidation products are formed from hydrocarbons.

1 E. G. Allison and G. C. Bond, Catalysis Revs., 1972, 7, 233 